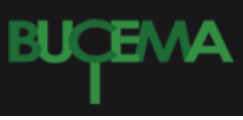

Bulletin du centre d'études médiévales d'Auxerre | BUCEMA

Hors-série $n^{\circ} 2 \mid 2008$

Le Moyen Âge vu d'ailleurs

\title{
Pecado e individuo en el marco de una antropología cristiana medieval
}

\section{Alejandro Morin}

\section{(2) OpenEdition}

1 Journals

\section{Edición electrónica}

URL: https://journals.openedition.org/cem/9552

DOI: $10.4000 /$ cem.9552

ISSN: 1954-3093

\section{Editor}

Centre d'études médiévales Saint-Germain d'Auxerre

Referencia electrónica

Alejandro Morin, « Pecado e individuo en el marco de una antropología cristiana medieval », Bulletin du centre d'études médiévales d'Auxerre | BUCEMA [En ligne], Hors-série $n^{\circ} 2$ | 2008, mis en ligne le 16 janvier 2009, consulté le 02 mars 2023. URL : http://journals.openedition.org/cem/9552 ; DOI : https:// doi.org/10.4000/cem.9552

Este documento fue generado automáticamente el 2 marzo 2023.

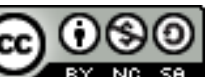

Creative Commons - Attribution - Pas d'Utilisation Commerciale - Partage dans les Mêmes Conditions 4.0 International - CC BY-NC-SA 4.0

https://creativecommons.org/licenses/by-nc-sa/4.0/ 


\title{
Pecado e individuo en el marco de una antropología cristiana medieval
}

\author{
Alejandro Morin
}

1 Quien aborda el estudio de las nociones de pecado y delito en la Edad Media contempla casi necesariamente la cuestión del individuo en la cultura medieval. Numerosas aristas del tema permiten vislumbrar las implicancias de una antropología de corte diferente en el análisis de la cuestión del pecado para este período.

2 Por un lado, la relación entre individuo y sociedad, con sus deslices tradicionales hacia visiones (tan decimonónicas) de un individuo «sumergido » en la comunidad, resulta un punto obligado cuando se estudia un tema como los castigos colectivos. Pero, por otro lado, el individuo mismo parece estar concebido de forma distinta a la formulación contemporánea y su relación con sus pecados y con su propio yo se efectúan en otros términos. Desde concepciones del pecado propio como exterior a la persona del pecador ${ }^{1}$ hasta la existencia de "apéndices" de la persona con incidencia en su conducta ${ }^{2}$, desde procesos de desdoblamiento del yo del pecador ${ }^{3}$ hasta la postulación de una autonomía del cuerpo o sus órganos con raíz en el pecado ${ }^{4}$, muchos son los ejemplos en que algunos vagos trazos de la antropología medieval obligan al estudioso de las nociones de pecado y delito en la Edad Media a repensar sus posturas.

Pero, amén de tales ejemplos, lo cierto es que existe además en la historia de Occidente una vulgata que plantea una epopeya del individuo (y del individualismo) con sucesivos jalones en los que el tema del pecado no es ajeno. La cuestión está habitada en general por trabajos que intentan dar con la partida de nacimiento del individuo en Occidente de forma de iniciar con ella la historia del individualismo propio de la cultura moderna. Así se lo ha hallado sucesivamente en el Renacimiento del s. XV, en el previo del XII o se ha postergado su parto hasta la Reforma y aún a la cristalización del pensamiento moderno del s. XVIII. La interiorización de la ética postabelardiana o el papel de la Reforma en la eliminación de los mediadores eclesiásticos para la salvación son algunos de estos eslabones en la cadena que lleva hacia el individuo moderno y en los que la cuestión del pecado se halla inserta. 
4 Esta historia puede ser desechada de plano en tanto mito historiográfico, tal como lo indica Jean-Claude Schmitt 5 . Pero es cierto también que en los siglos finales de la Edad Media se registran transformaciones signficativas en torno del sacramento penitencial y de los dístintos órdenes normativos que rigen en la Cristiandad, cambios que inducen a pensar en términos de un proceso de individuación y a buscar formas específicas y configuraciones posibles de la subjetividad en la Edad Media, que pueden forjarse a partir de mecanismos religiosos y jurídicos del momento sin que éstos generen un tipo de singularidad interior como la que caracteriza al individuo moderno y del cual aquellas no necesariamente deben aparecer como sus antecedentes.

5 El estudio de las relaciones entre pecado y delito en el marco de la antropología cristiana medieval, entonces, se ubica casi naturalmente en la cuestión de la subjetividad y el individuo. Ahora bien, la mayoría de los estudios que abordan el problema, lo han hecho en función, bien de la discusión en torno del surgimiento del individuo, bien del debate sobre la pertinencia misma de la cuestión, en los términos en que fue planteada. En efecto, gran parte de la bibliografía dedicada a la subjetividad cristiana medieval recala casi obligadamente en la larga discusión sobre la emergencia del individuo en la Edad Media. Los trabajos que se encuadran en este marco se dividen, siguiendo un esquema diseñado por J.-C. Schmitt, en dos corrientes ${ }^{6}$.

6 Una está centrada en el rol del individuo en relación con el Estado y la organización política. A esta corriente se la conoce como teológico-política y conformó la primera elaboración historiográfica del descubrimiento del individuo a partir de trabajos alemanes de la segunda mitad del s. XIX, como los de Jakob Burkhardt o de Otto von Gierke. Dentro de esta corriente teológico-política, los trabajos de Walter Ullmann trajeron la novedad de ubicar los núcleos más importantes de este proceso, no al final de la Edad Media, sino en la Edad Media central. Forma parte de lo que en su momento se llamó la « rebelión de los medievalistas ».

7 La segunda corriente señalada por Schmitt es la que, sin negar la importancia del individuo político, se centra en la emergencia o agudización de la conciencia del individuo consigo mismo. Se trata de un área de investigación muy frecuentada desde la década del 70. Esta opción historiográfica resulta un campo más fértil para una reflexión en torno del pecado en la Edad Media. En efecto, entre las áreas más frecuentadas para estudiar este proceso, además del desarrollo del género biográfico y el retrato, la transformación de las técnicas intelectuales y las mutaciones de la afectividad y la espiritualidad, se encuentran también las nuevas concepciones del pecado y de la penitencia y la interiorización de la vida moral.

Los cuestionamientos al « despertar de la conciencia »

8 En esta segunda corriente, hay una serie de autores ya clásicos como Colin Morris ${ }^{7} \mathrm{o}$ John Benton ${ }^{8}$, a los que también se podría sumar José L. Romero ${ }^{9}$. En ellos, se postula una historia del nacimiento o redescubrimiento del individualidad, a partir del s. XII aproximadamente. No nos detendremos en estos textos sino en los que plantearon cuestionamientos a esta postura.

9 El primero de ellos es el que ofrece un artículo de Caroline Walker Bynum ${ }^{10}$. Este apunta a discutir la caracterización de la vida religiosa y literaria del XII como un «descubrimiento del individuo». Su intención no es contradecir los análisis previos sino ubicarlos en un contexto más amplio y más precisamente definido. En este sentido, Bynum plantea ubicar tal «descubrimiento del individuo ", a menudo presentado como resultado de una " pérdida de la comunidad » - en tanto control y en tanto apoyo -, en 
el contexto de un también nuevo interés del s. XII por la pertenencia autoconsciente a grupos y por el cumplimiento de roles sociales. Propone reemplazar la idea de un «descubrimiento del individuo» por la de un «descubrimiento del yo ». Pero ello conformaría tan sólo la mitad de la historia, en tanto el mismo siglo presenció un creciente interés por las relaciones humanas. La personalidad, para Bynum, queda caracterizada tanto por el descubrimiento del paisaje interno y del yo como por el descubrimiento del grupo de pertenencia y el hombre exterior; incluso es posible establecer una relación causal entre ambos procesos.

10 Jean-Claude Schmitt ${ }^{11}$ retoma en principio esta postura de Bynum pero, además, plantea a la emergencia del individuo como una de aquellas ficciones que inevitablemente los historiadores hacen intervenir en sus prácticas, pese a que la lógica del discurso histórico reposa precisamente sobre el gesto de enunciación del desmontaje de ficciones. Schmitt postula, por un lado, la necesidad de desbrozar el terreno léxico y conceptual en tanto las expresiones que se utilizan para describir los fenómenos pecan de una gran ambigüedad. Pero, por el otro, también se trata de ampliar la problemática de forma tal de abordar la noción de persona en el mundo medieval, cuestión fundamental dejada de lado por los historiadores de ambas corrientes. Si ha de aceptarse la pregunta sobre si el s. XII descubrió al individuo, Schmitt plantea, por lo menos, la necesidad de una respuesta matizada. Y ello en función de la evidencia más clara, la ausencia en la Edad Media de una noción de individuo en el sentido contemporáneo del término. La noción utilizada por los hombres de la época es la de persona, ambigua y contradictoria, en tanto por un lado implica la disolución del sujeto en Dios o el pueblo cristiano pero, por el otro, esa disolución se produce tras un proceso de autoconocimiento que favorece la práctica de la introspección.

11 El último texto que trata la cuestión del individuo en la Edad Media que relevaremos aquí es el de Aaron Gurevich ${ }^{12}$ sobre los orígenes del individualismo europeo. Allí intenta formular una serie de distinciones conceptuales para superar algunos puntos muertos de la discusión. En primer lugar, el sesgo social : la mayoría de los estudios previos ignora las diferencias sociales en su análisis de la cultura medieval. En segundo lugar, el teleologismo. Para Gurevich, es necesario descartarlo de una vez y explicarse cómo era el hombre de la antropología medieval, es decir, analizar cómo la religión y la cultura de la época crearon una atmósfera general que establecía límites dentro de los cuales se podía descubrir una individualidad, cuyos rasgos concretos, a su vez, sólo se adquirían dentro de una red de relaciones grupales. Por último, la confusión de dos registros estrechamente conectados pero esencialmente diferentes: los autores criticados por Gurevich funden en una misma mirada individualidad y personalidad, con lo que hacen derivar todo estudio sobre la personalidad en la Edad Media en una historia del individualismo en Occidente.

Gurevich define a la personalidad como « cualidad inalienable de la esencia del hombre que vive en sociedad. Pero en los distintos sistemas socioculturales la personalidad adquiere cualidades específicas. La personalidad es la que define a un individuo humano, inmerso en unas condiciones sociohistóricas concretas (p.19).» El individuo interioriza el sistema de coordenadas culturales que la sociedad le propone. Una vez asimilados, se convierte en una personalidad. Gurevich plantea como metodología de trabajo una fusión entre los enfoques individualizador y generalizador : para ello, la cuestión de la originalidad individual resulta no sólo independiente sino incluso carente de pertinencia. En 
cambio, la personalidad, inevitablemente unida a la cultura de su tiempo y absorbiendo su visión del mundo y sistema de valores, aparece como una entidad intermedia entre cultura y sociedad. Gurevich dedica también gran parte de su atención a la noción de persona en la Edad Media así como también a la historia de este concepto. Para este autor resulta imprescindible reconocer que el status de persona está dado por el hecho de que bajo el cristianismo la persona adquiere un alma individual. Pero lo que se deduce del análisis de la historia de este concepto es un débil desarrollo medieval de los aspectos antropológicos, que da cuenta de la morosa y difícil mutación de la persona/ máscara en personalidad. La razón radica en la conciencia de una persona dominada por la idea de Dios, mientras que, sobre el hombre, sólo recae su reflejo.

Ahora bien, Gurevich confiesa que el intento por esbozar la personalidad medieval deriva en gran parte en una exposición de las dificultades del historiador ante esta tarea en tanto la personalidad permanece siempre oculta a su mirada. A partir de esta situación, surge la hipótesis de la futilidad de todo intento en este sentido. Se plantearía así una objeción de carácter general : no existe un individuo a atrapar por detrás del conjunto de fórmulas y topoi que le ofrece su cultura. La lengua por medio de la cual se expresa el individuo esconde también su esencia. Ante esta impugnación radical, Gurevich responde con una declaración de principios: se debe reconocer en el individuo un plano de contenidos, esencial, que se oculta tras un plano de expresión (planos que en principio nunca han de coincidir). Es a partir de estas observaciones que Gurevich responde a la pregunta sobre el descubrimiento de la personalidad/ individualidad en la Edad Media sobre la base de los mecanismos de expresión. El proceso de manifestación y transformación de la personalidad en individualidad presenta un avance discontinuo que desmiente en última instancia una relación de herencia entre la personalidad medieval y la contemporánea, cada una específicamente irrepetible.

Los dispositivos de construcción de la antropología medieval

El desarrollo del debate sobre la emergencia del individuo en la Edad Media permite concluir en un claro imperativo de analizar la antropología cristiana en sus propios términos y atender particularmente a sus específicos marcos conceptuales que crean principio de subjetividad. Ahora bien, a nuestro entender, se puede postular a la antropología cristiana medieval como una construcción que depende del dispositivo discursivo e institucional que la construya. Operan en el campo distintas formas de concepción del sujeto que se encuadran en distintos dispositivos, como lo señala Bartolomé Clavero al remarcar la diferencia existente en la concepción de la persona individual entre los juristas, por un lado, $\mathrm{y}$ « iuxta theologos et physicos ", por el otro ${ }^{13}$.

El dispositivo teológico atiende a la construcción del yo, en principio, sobre la dualidad cuerpo/alma, es decir, la conjunción de un cuerpo carnal y perecedero y de un alma espiritual, incorpórea y perenne. Se trata, al decir de J. Baschet, de una concepción dual, no necesariamente dualista ${ }^{14}$. Ahora bien, esta construcción se ve a menudo complicada por varios elementos (también señalados por Baschet) como es el caso de los frecuentes deslizamientos hacia una antropología de tipo ternario sobre la base de una tríada cuerpo-alma-espíritu.

Este dispositivo teológico lleva la voz cantante dado el lugar que ocupa la teología en el mundo medieval, ámbito donde se formulan los principales fundamentos ideológicos de una sociedad estructurada por la Iglesia. Pero como la teología no abarca todo ni implica un cuerpo de dogmas unificados e inmutables, es de remarcar que el dispositivo 
teológico en absoluto constituye un bloque homogéneo. Y, por otra parte, la relación entre los dos términos, cuerpo y alma, es inestable a lo largo del período estudiado. En efecto, los siglos XII y XIII conforman precisamente un período de cambio y debate en torno de la psicología del alma en el ámbito de la teología.

Este período es el que asiste a la introducción de una psicología que absorbe de manera dispar las categorías aristotélicas y que desecha o, más bien reformula, una psicología de corte neoplatónico que tenía a Agustín como figura fundadora. En el siglo XII se comienza a percibir una suerte de insatisfacción frente a las concepciones agustinianas del alma, sentimiento de insuficiencia que explica el interés de los escolares de la época por buscar en nuevos textos el encuadramiento de sus necesidades. La conformación de una nueva psicología en el s. XIII se hará en un contexto de debate, particularmente en torno de dos puntos : la articulación alma/cuerpo y la unidad o multiplicidad de las instancias del alma. Se trata de debates donde la noción de persona juega un rol central y donde se asistirá a una creciente complejización del alma. Este desarrollo conceptual se dará, por otra parte, en el contexto de fuertes contestaciones a la ortodoxia eclesiástica sobre la base del dualismo.

Los trabajos que se pueden consultar para describir los trazos generales de estos dispositivos son de variado tenor. En efecto, componen un conjunto heterogéneo $\mathrm{y}$, pese a algunas coincidencias de contenidos, su único denominador común es el de la utilidad que ofrecen para repensar las nociones de pecado y delito en el marco de un estudio de la subjetividad cristiana medieval.

El dispositivo teológico

Hallamos así autores, como Sigfried Wenzel o Donald Howard, que relacionan las diferentes teorías psicológicas medievales con la cuestión del pecado, en particular, los esquemas generales de presentación de pecados ${ }^{15}$. S. Wenzel, en su trabajo sobre el esquema de los siete pecados capitales analiza tres formas clásicas de presentación del mismo : la concatenación, la explicación psicológica y la cosmológica o simbólica ${ }^{16}$. Todas ellas conforman, en realidad, explicaciones psicológicas, en tanto en su base se hallaba la noción de que el vicio significaba una corrupción del alma. Teniendo esto como punto de partida, para llegar a los vicios capitales, se necesitaba simplemente encontrar una división lógicamente satisfactoria del alma o algo conectado con ella, tarea muy del gusto de los escolásticos. Este esquema sufre importantes modificaciones en el s. XIII : la concepción de que los vicios son corrupciones del alma deja lugar a otra visión más restringida, al integrar los vicios a los diversos mecanismos de la volición, es decir, pensarlos como direcciones erróneas de la voluntad.

D. Howard, por su parte, trabaja con el esquema de las tres tentaciones (1 Juan 2, 16), muy utilizado en la psicología cristiana en tanto se presenta a la vez como lista de pecados y como descripción del " process of sining ${ }^{17}$. En efecto, la tradición asocia la fórmula de las tres tentaciones con una "psychological description of sin as it occurs within the soul " (p. 56), es decir, con la progresión agustiniana sugestión/delectación/consentimiento. Este esquema, toma su forma en la noción de la tripartición del alma : la fórmula sugestión/delectación/consentimiento describe al pecado comenzando con la pasión que influencia a la voluntad y termina cautivando a la razón. La fórmula bíblica resulta en principio muy gráfica respecto de los peligros para el alma cristiana. Sin embargo, su análisis más minucioso y su articulación con las categorías de la psicología medieval genera largos debates entre los teólogos de los siglos XII y XIII. A medida que tal psicología se va complejizando con el aporte aristotélico, la fórmula de las tres 
tentaciones comenzó a resultar inadecuada. Esto se evidencia en los análisis de Tomás de Aquino sobre el process of sining.

El dominio de la razón sobre la carne es el tema central de varios trabajos que abordan la cuestión desde distintos escenarios, análisis de casos puntuales puestos en juego en los debates del s. XIII sobre la articulación entre el cuerpo y el alma.

Uno de ellos es el de Dyan Elliot sobre el tratamiento teológico y canónico de las poluciones nocturnas ${ }^{18}$. Las emisiones nocturnas, en particular las de los clérigos, conforman desde la época patrística un tema de reflexión para los hombres de Iglesia. En principio, la discusión va unida a la cuestión de la pureza que debe regir al oficiante del milagro operado en la misa. Sin embargo, atiene también a la antropología medieval en tanto este fenómeno traduce una insubordinación del cuerpo que pone en cuestión el esquema de desarrollo del pecado o process of sining representado en la tríada Serpens/ Eva/Adam. En efecto, con las emisiones nocturnas se produce una operación autónoma del cuerpo, una acción perturbadora para la cual la razón no ofreció consentimiento alguno. Este factor es el que induce a la mayoría de los teólogos a comprometer su esfuerzo en la tarea de borrar cualquier contenido pecaminoso en la polución. Sin embargo, la creciente importancia que recibe el sacramento de la eucaristía durante la Edad Media implicará asimismo una creciente tematización de las poluciones en el ámbito canónico, en un proceso que conllevará cierta dosis de diabolización y un mecanismo de exteriorización de una interioridad que se concibe peligrosa.

Un proceso similar de diabolización de las autonomías corporales es el que analiza Alain Boureau en su trabajo sobre el sonambulismo ${ }^{19}$. Para este autor, el sonámbulo representa la impugnación más radical a la tesis de la dominación del cuerpo por el alma : puro órgano, en él no se revela el dominio de ninguna de las potencias del alma. Boureau señala un período de breve pero intensa tematización del sonambulismo hacia fines del s. XII y principios del XIII. Tres son los escenarios principales de este proceso: el discurso naturalista y médico, la crónica y el derecho canónico. Esta tematización se contextualiza para el autor en la explosión de la unidad de la antropología cristiana que originaron la invasión de los saberes naturalistas y el paralelo refinamiento de teorías neoagustinianas y platonizantes del alma. El sonambulismo permitía a principios del s. XIII jerarquizar las diferentes corporeidades del hombre. En este contexto intelectual, se convierte en un caso de escuela para las disputas quodlibetales de finales del s. XIII acerca de la articulación entre el cuerpo y el alma.

Otro texto que analiza la inclusión en quaestiones quodlibetales de reflexiones en torno de la corporeidad es el que ofrece Caroline Walker Bynum en su trabajo sobre el tópico de la continuidad material respecto de la reconstitución de cuerpos tras el Juicio Final ${ }^{20}$. Mientras que en los trabajos de Elliot o Boureau se presenta la idea de un cuerpo en última instancia autónomo frente al yo, del artículo de Bynum se rescata un aspecto diferente, la idea de un cuerpo inescindible de la persona, una asimilación entre el cuerpo y el yo. Analizando tales quaestiones, Bynum señala su sorprendente literalismo extremo y el materialismo que impregnan las discusiones en torno de la teología del cuerpo de los siglos XII y XIII. Ahora bien, los teólogos escolásticos presentan un amplio consenso respecto de la estimación crucial del cuerpo en la naturaleza humana, es decir, su carácter necesario para definir a la personalidad. El problema girará más bien en torno de cómo se relacionan parte y todo en función de la identidad personal. El tema de la continuidad corporal se ubica entonces en la historia de las teorías platónicas y aristotélicas sobre el alma. El dualismo platónico que domina hasta el s. XII 
postula al hombre como un alma que tiene un cuerpo que a la vez le sirve de instrumento y de prisión. La definición aristotélica que hace irrupción en el XIII es radicalmente diferente: el alma es la forma del cuerpo y la persona sólo puede concebirse como hilomórfica unión de cuerpo y alma : la victoria sobre el dualismo que plantea esta tesis se manifiesta en la definición de Tomás « anima mea non est ego ». Un trabajo en una sintonía similar, análisis de la incidencia del hilomorfismo en las definiciones antropológicas medievales, presenta también el estudio de Tullio Gregory sobre las quaestiones en torno del estatuto humano o divino de Cristo durante el triduum ${ }^{21}$. La adopción de la teoría del alma como forma sustancial única del compuesto humano obliga a los teólogos a plantear la no humanidad de Cristo una vez que su cuerpo devino cadáver. Pero al mismo tiempo genera una serie de problemas dogmáticos en un núcleo central del cristianismo: desde el momento en que no se puede postular una identidad entre el cadáver y el cuerpo vivo, entonces Cristo estaría asumiendo en la resurrección un cuerpo distinto. En la misma publicación, el número de Micrologus dedicado al cadáver, hallamos también el trabajo de Maaike van der Lugt sobre la reanimación angélica o demoníaca de cuerpos muertos ${ }^{22}$. La conformación desde el s. XII de una teoría de los corpora assumpta pone en juego los conceptos que permiten, por un lado, precisar la definición del hombre a partir de la dualidad alma/ cuerpo, y por el otro contrastar con un caso específico la lista de criterios de definición de lo se considera vida.

La articulación alma-cuerpo es analizada también en el citado artículo de Jerôme Baschet. Síntesis muy clara de las concepciones medievales sobre el alma y el cuerpo, este trabajo atiende no sólo a la estructura de la persona según estas representaciones sino también a su dinámica. De este modo se interroga sobre las modalidades de asociación e interrelación entre cuerpo y alma, dando cuenta del desarrollo desde los s. XII y XIII del tema de la amistad entre el cuerpo y el alma, es decir, de su conmensurabilidad y de la cualidad de unibilitas, atribuida al alma para unirse al cuerpo. El autor se pregunta asimismo sobre las significaciones sociales de estas formulaciones con el objeto de ver allí una matriz ideológica fundamental de la sociedad medieval : en este sentido, la idea del cuerpo glorioso ofrece un horizonte de articulación jerárquica cuerpo/alma que impone a esta última como principio social.

El dispositivo jurídico

27 Los últimos trabajos que comentaremos en este apartado apuntan, ya no a la concepción del sujeto desde el dispositivo teológico, sino desde el jurídico. En ellos, nos centraremos claramente en las formas de construcción del sujeto de derecho. El primero de estos trabajos pertenece a Yan Thomas ${ }^{23}$, un texto donde se encuadra la historia del concepto de persona en el marco de discusiones jurídicas contemporáneas. Persona remite a un artefacto técnico del discurso jurídico: proviene del arte dramático, pasa pronto al derecho romano donde se complejiza infinitamente. En efecto, en el teatro, la persona refiere un desdoblamiento actor/personaje pero ambos son siempre igualmente individuales. En el derecho, en cambio, un mismo individuo puede hacerse cargo él solo de varias personas o varios individuos concretos pueden tener una sola persona como soporte. El derecho disocia los sujetos y los cuerpos para componer personas : la unidad de la persona no remite en primer lugar a la del sujeto físico o psicológico sino que ante todo refiere a la unidad de un patrimonio.

Esta concepción de la persona en el derecho romano resulta difícil de aceptar en el mundo medieval. Los comentadores del derecho romano « rebajan el círculo de la persona 
al sujeto humano concreto » (p. 95). La antropología vigente en la época parece operar de tal forma que lleva a los comentadores a adaptar las fórmulas « extrañas » a sus ojos. La tarea de traducción de los juristas medievales tiende a enfatizar la necesaria adecuación de la persona y el individuo y para ello se recurre al mecanismo de la «representación ». Este permite leer las soluciones del Corpus salvando el principio de singularidad de las personas. Para los juristas medievales, la verdadera "persona " parece remitir naturalmente a la persona individual, al contrario de la tradición jurídica romana.

Otro autor que trabaja como Thomas el concepto de persona en el dispositivo jurídico integrado aquí con el teológico - es Alain Boureau ${ }^{24}$. Ahora bien, si en algún punto coinciden estos autores - respecto de la persona en el mundo jurídico medieval como artefacto técnico de duplicación del individuo -, lo cierto es que lo hacen a través de caminos inversos. Boureau parte de la doble revolución intelectual en el campo del derecho y del de los estudios sacros que se produce entre los siglos XII y XIII : la ruptura que se produce en el nacimiento conjunto de ambos campos implica un nuevo régimen de la verdad, percibida, según Boureau, como construcción o reconstrucción - en contra de la tradición, la narración y la costumbre. Se trata de la constitución de una común matriz intelectual.

30 En este contexto, el análisis del concepto de persona se entiende como punto de aplicación de aquel cuestionamiento fundamental de la episteme escolástica. La persona como sujeto de la ley es, para Boureau, una originalidad del derecho canónico medieval con la noción de " persona moral » o « persona ficticia ». Esta proviene del desarrollo de las corporaciones y del Estado. Para Boureau, la novedad de la elaboración medieval del concepto de persona radica en designar con aquel vocablo a las instancias abstractas dotadas de capacidades jurídicas, cuando en el derecho romano sólo refería a individuos singulares. Las divergencias con el análisis de Yan Thomas son evidentes en cuanto a cómo calibrar el rol del concepto de persona en el derecho romano y su tratamiento por los juristas medievales.

31 La teología escolástica del s. XIII, por su parte, trabajó la noción de persona de una manera análoga a la del campo jurídico, pero de forma autónoma en un proceso muy largo con una inflexión importante en el s. XIII. La emergencia en el s. XII de contestaciones a la ortodoxia bajo la forma de dualismos radicales, el refinamiento por parte de los nuevos saberes naturalistas del conocimiento del cuerpo, la introducción en Occidente del De anima de Aristóteles, etc., vinieron a plantear las condiciones de un debate en cuyo centro se hallaba la noción de persona. Éste se dio entre los partidarios de una forma sustancial única en el hombre o tesis conjuntiva (Tomás de Aquino) y los de formas sustanciales múltiples o tesis disyuntiva - neo-agustinianos, numerosos en las corrientes franciscanas. Sin embargo, lo que le interesa remarcar a Boureau es que tanto una corriente como otra coinciden en concebir a la persona de forma independiente del individuo, al igual que lo hace el derecho.

Por último, otro trabajo que apunta a la figura del sujeto de derecho es el que ofrece Bartolomé Clavero cuyas consideraciones atienen tanto a la Baja Edad Media como a la Edad Moderna ${ }^{25}$. En él, se refuerza la idea de la distancia entre personas e individuos en el dispositivo jurídico. Para este autor, se trata de analizar a las sociedades medieval y moderna desde una mirada antropológica. Y ésta, que permitiría comprender la estructura del mundo moderno antes que la génesis del mundo contemporáneo, sólo puede dar frutos si atiende esencialmente al testimonio de la jurisprudencia del ius 
commune o a la reconstrucción de su antropología. Una antropología en la que no existe "la persona que pudiera ser unitariamente sujeto de un derecho privado, ni el Estado que singularmente pudiera a su modo serlo de un derecho público » (p. 37).

Se trata de una armazón conceptual en la que los sujetos exclusivos del sistema son las personae fictae. Las personas ficticias, por otra parte, no aparecen como especies de cuerpos intermedios y ello es así por cuanto los extremos de referencia (Estado e individuos) no tienen sustancia real. La condición individual se determina como mero soporte de un status. La persona ficta no viene a complementar a la persona individual sino que realmente la suplanta. La concepción de la personalidad individual pertenece al discurso de los teólogos y los médicos pero es jurídicamente inexistente. Para los theologos et physicos, la persona es esencialmente singular y no susceptible de desdoblamiento ni reduplicación. No ocurre lo mismo con el discurso de los juristas que arman un sistema de privilegios sin sujetos personales : la doctrina del derecho común opera sustancialmente con derechos sin sujetos.

Pecado y delito en el marco de una antropología medieval

Los textos anteriormente reseñados nos sirven como background conceptual para nuestra intención de analizar la cuestión del pecado en función de los distintos dispositivos de construcción de la subjetividad. La puesta en relación de los registros teológico y jurídico nos resulta crucial en virtud de nuestro presupuesto de una antropología construida sobre la base de dispositivos discursivos e institucionales. En este sentido, nuestro supuesto dista de la idea de una personalidad esencial que se esconde detrás de un " formulaico plano de formas » ${ }^{26}$. Se trataría más bien de pensar a los dispositivos, no como planos de expresión/ocultamiento de la personalidad, sino como múltiples fuerzas constitutivas de la misma. Fuerzas de cuya confrontación sólo situacionalmente se puede determinar el vector resultante. Nos parece, pues, más productivo pensar a la persona como el vector de las múltiples fuerzas que operan en su diseño más que como una subjetividad planteada como esencia verdadera (indefectiblemente) oculta tras las máscaras.

35 En este sentido, resulta fundamental recalcar la pluralidad de dispositivos que operan en el campo. Esta multiplicidad nos permite por otra parte evitar la sensación de asfixia que generan ciertos trabajos construccionistas, en cuanto a una determinación absoluta por parte de las coordenadas sociomentales de un período - desearíamos así evadir la "run but you can't hide " constructionist thesis, al decir de Nancy Partner ${ }^{27}$. Si se postula a la antropología medieval como una construcción, esto significa que, como tal, se trata de una construcción fallada. Desde este punto de vista, parece más provechoso pensar la posibilidad de emergencias subjetivas, es decir, actos de fuerza fuera de régimen que prosperan, precisamente, en la pluralidad de dispositivos.

Dicho esto, es de remarcar que la interacción de los dispositivos de construcción antropológica no parece ser un área muy frecuentada por los medievalistas. La interacción entre los discursos teológico y médico puede constatarse en varios de los autores que hemos mencionado. Pero de la interacción entre teólogos y juristas en cuanto a la noción de persona sólo tenemos el trabajo de Boureau que apunta a la idea de una matriz común de pensamiento ${ }^{28}$. Esta observación general se aplica de manera más concluyente si restringimos la mirada a los historiadores que estudian las relaciones entre pecado y delito en la Edad Media, aunque cabe señalar que se trata de un conjunto reducido de autores, de los cuales la mayoría, además, aborda la cuestión de manera tangencial a sus preocupaciones centrales ${ }^{29}$. Salvo el trabajo de 1990 de 
Bartolomé Clavero - que atiende específicamente a la relación pecado/delito, pero encarada en términos del siglo XVII ${ }^{30}$-, sólo hallamos la obra monumental de Paolo Prodi sobre el pluralismo de los fueros en el mundo jurídico medieval y su derivación posterior en el moderno dualismo entre moral y derecho.

Este texto reviste un particular interés para nuestro propósito por cuanto hace intervenir en su argumentación la cuestión del individuo en el seno de una historia, prácticamente única, de la relación entre pecado y delito hasta la época contemporánea. Un rasgo importante de esta obra es su (explícita) perspectiva totalizante, abarcativa y de larga duración, base, por otra parte, de una de las múltiples virtudes del texto, la de incursionar en un área evitada por muchos autores como es la del estudio de las relaciones pecado/delito en el largo plazo de la historia general del cristianismo. Prodi elige para ello trabajar en un plano general y doctrinario, evitando la casuística y la especificación en determinadas figuras del derecho o la teología moral. Una perspectiva que también se encuadra como historia institucional para un estudio de la problemática del pecado, habitualmente reservada a la historia de las mentalidades o la historia social.

Ahora bien, cuando este texto hace operar en su seno la cuestión del individuo, lo hace adscribiendo a los términos en que ésta fuera planteada por la corriente teológico-política. Así, por ejemplo, hace uso de autores como Louis Dumont ${ }^{31}$, quien desde el análisis antropológico continúa la labor de los historiadores que habían pensado el nacimiento del individuo en función de su relación con las corporaciones y el Estado. Esta adscripción cuadra en algún punto con la perspectiva general que el autor optó para diseñar su estudio, y se puede suponer para ello una concordancia básica en contenidos y metodología. Pero esta conjunción entre corriente teológico-política y perspectiva general no sólo desatiende los dispositivos de construcción antropológica sino que deja de lado la idea de estudiar la antropología cristiana medieval en sus propios términos. Allí radica tal vez el uso del término « individuo » en contextos muy disímiles o el interés por ligar con el individuo moderno las referencias al tema antiguas o medievales. Incluso el texto parece recaer en la narración de la epopeya del individuo con sus sucesivos " nacimientos », que en este caso se remontan al judaísmo antiguo, pasando por el s. XII para cuajar hacia el s. $\mathrm{XV}^{32}$. En un punto, la perspectiva general y doctrinaria que plantea Prodi, muy útil en otros aspectos, puede resultar contraproducente.

En contraposición - y sin querer desmerecer en nada un trabajo monumental y de profunda riqueza como el de Prodi - querríamos plantear la necesidad de hacer conjugar con el relato a gran escala análisis que emerjan de una pespectiva situacional, es decir, del estudio de escenarios concretos donde el binomio pecado/delito y la cuestión de la persona se entiendan en función de la antropología cristiana de acuerdo con sus específicos marcos de construcción.

A nuestro entender, para el estudio de relaciones pecado/delito en la Edad Media, una perspectiva situacional resulta metodológicamente fundamental. A partir del vocabulario empleado y las infinitas interrelaciones existentes entre el discurso jurídico y el religioso en la Edad Media, si uno se posiciona en una perspectiva general, tiende a ver al pecado y al crimen como áreas indiferenciables, como si la fusión entre estos dos registros pudiese ser total. En todo caso, si se señala su mutua autonomía pues la existencia de una doble tradición textual y profesional es evidente -, se plantea una relación de tipo acumulativo, tal como la definió Bartolomé Clavero : pecados son los que aparecen en las prescripciones religiosas; delitos, los que a su vez aparecen en 
los textos jurídicos ${ }^{33}$. En términos medievales, esta preocupación se expresaba en torno de la relación entre el forum conscientiae y el forum exteriore. De esta forma, los juristas y moralistas de la Baja Edad Media y primera Edad Moderna articulaban dos premisas de general aceptación. Por un lado, la Iglesia reclamaba un derecho de autonomía legislativa respecto de un orden laico al que desplazaba a un segundo plano. Por otro lado, al decir de un jurista del s. XVI, «leges autem in foro conscientiae servanda esse nemo dubitat » ${ }^{34}$ : la concordancia y simultánea subordinación a los dos órdenes normativos se tomaba como axioma.

Ahora bien, aplicadas a casos concretos, estas premisas no necesariamente resultaban conjugables y, desde este punto de vista, una perspectiva centrada en figuras específicas puede ofrecernos un panorama bien distinto. Permítasenos ejemplificar con un caso ajeno a la cuestión de la antropología medieval. Según las Partidas de Alfonso el Sabio - corpus central de nuestra investigación -, quien hallase a su esposa en adulterio puede matar sin pena tan sólo al amante y siempre y cuando este sea reputado « ome vil ». Estas condiciones se piensan como un freno a las facultades homicidas del marido, paralelas a las que posee también el padre de la adúltera. Si se hace una proyección hasta el s. XVI, lo que se apreciará, sin embargo, es una decidida tendencia en la legislación castellana hacia la consolidación del ius occidendi del marido respecto de su mujer adúltera. Este reforzamiento del poder marital alcanza también a otras formas de unión matrimonial menos formales e implica una clara opción por la aplicación de la pena capital a las adúlteras. Esta tendencia se contrapone claramente a lo estipulado tanto en el derecho canónico como en el ius civile, el cual - tras la corrección efectuada por la Novela 134 - expresamente proscribía el uxoricidio en el régimen del crimen flagrante y suplantaba, en caso de sentencia judicial, la pena de muerte a las adúlteras por la de reclusión.

Uno se puede plantear cómo se compatibiliza la legislación laica castellana y su tendencia a amparar al uxoricidio en caso de adulterio, con una normativa canónica que claramente lo condena. Lo que aparece en juego aquí es la relación entre lo que es pecado para la Iglesia y crimen para la ley laica. En efecto, en el caso del homicidio de la adúltera nos hallamos ante un punto de inconsistencia del axioma de la concordancia y simultánea subordinación a los dos órdenes normativos: lo que para la Iglesia es pecado mortal, es para la legislación laica un derecho. No se trata de algo que la ley se abstiene de castigar sino algo que protege y regula. Allí, en la subversión de la relación acumulativa de concordancia y prelación que mantienen entre sí el forum conscientiae y el forum exteriore, reside la quaestio que desarrollan juristas y moralistas : Peca mortalmente quien, haciendo uso de la ley, mata a su mujer adúltera ? Esta cuestión halla una forma de resolución, que se puede rastrear en comentadores del s. XVI como D. de Covarrubias y Tomás Sánchez que se remiten a la tradición hispana desde el final de esta evolución. La resolución que plantean opera sobre un doble registro. En efecto, se trata de hacer del uxoricidio/pecado, bien una forma de homicidio legítimo, bien un pecado que la ley no castiga.

En cuanto a la primera operación, los comentadores resguardan la moralidad del uxoricidio si éste se produce tras una sentencia judicial por adulterio. Aquí la argumentación se centra en la licitud de la pena de muerte y en la ausencia de pecado en los actos de los verdugos. La segunda operación atiende al uxoricidio dentro del régimen del crimen flagrante, de cuya pecaminosidad no cabe duda alguna. Por ello, los comentadores se ven obligados a pasar a discutir la legitimidad de la ley humana que 
avala un pecado mortal. La solución pasa por dictaminar que el homicidio por adulterio conforma un pecado que la ley se abstiene de castigar. Así, la coherencia de la relación acumulativa pecado/delito queda a salvo. Para ello, se hace necesario poner en juego una distinción clave acerca de si la ley permite o si concede y/o aprueba. La cuestión en el fondo pasa por diferenciar lo que está mal pero que, por alguna razón, la ley no castiga y lo que no está mal. Los encargados de hacer esta concordia discordantium tienen como tarea eliminar la posiblidad de que un pecado sea una facultad legal. Por ello, afirman que las leyes no aprueban sino que dejan pasar. Dejan impune pero no protegen un derecho. El problema aquí es que los textos legales no se reducen fácilmente al sentido que los comentadores pretenden imprimirle. En todo caso, la lógica del sistema se garantizará en última instancia impugnando directamente la legitimidad de una ley que apruebe y conceda lo que la moral eclesiástica condena.

Este ejemplo revela un punto de ruina que el trabajo de interpretación de los juristas oculta tras una operación de sutura asaz delicada. Al igual que en otros puntos de la vida social, la lógica de comportamientos de los sectores laicos se contrapone a la tradición jurídica avalada por la Iglesia. Estas estrategias de conducta autónomas entran en obligado diálogo con la preceptiva eclesiástica. Pero la sanción de una legitimidad legal para algo que la moral eclesiástica considera pecado mortal produce efectos distintos a los del tradicional juego de omisiones en uno y otro orden normativo. Pone en entredicho las relaciones de concordancia y prelación moral/ derecho que los habitantes de este sistema postulan y practican.

La perspectiva situacional que aquí postulamos no radica sólo en atender a figuras específicas. También implica mantenerse en el registro textual en que se da determinada reflexión sin "extraer ", en el sentido de independizar de los enunciados particulares en que se realiza, una determinada «concepción ». Por ejemplo, si se rastrean las elaboraciones alfonsinas en torno del process of sining o desarrollo psicogenético del pecado - dato clave para delinear la antropología operante en estos textos. lo que se constata es que tales elaboraciones giran en torno de un problema concreto, la descripción de las maneras de pecado que borra el sacramento de la penitencia, y se expresan a través de un mecanismo textual particular, las lecturas alegóricas de la metáfora de los tres muertos, es decir, de los tres resucitados por Jesús según el Evangelio : la hija de Jairo, el principal de la sinagoga, el hijo de la viuda de Naín y Lázaro.

46 La lectura más frecuente de los tres muertos es la que reconoce en ellos tria genera peccantium. A partir de una ecuación simple que identifica el pecado con la muerte del alma se monta una imagen que opera sobre el par penitencia/resurrección. Si se analizan las fuentes eclesiásticas, se registran cuatro esquemas principales de interpretación alegórica (no necesariamente excluyentes entre sí) :

- In corde - in opere - in consuetudine: se trata del esquema más frecuente. Clasifica los pecados en función de sus modalidades y con los ojos puestos en la escala de agravamiento. La puella representa la muerte del alma cuando brinda su consenso al deseo pero no ha procedido aún al acto. El juvenis ha pasado efectivamente a los hechos, lo que queda graficado en la salida del domus. Finalmente, Lázaro encarna la perdición en el pecado consuetudinario ;

48 - In occulto - in publico - in consuetudine : atiende a otro aspecto de la temática del pecado, su nivel de interioridad o exterioridad : Tanto este esquema como el anterior se derivan de la conjugación de la imagen bíblica de los tres muertos con la bipartición del pecado 
en torno del par cor/opus. Implica la puesta en relación con la tríada sugestióndelectación-consenso. Esta preocupación por el grado de publicidad del pecado se conecta en un punto con el interés teológico y canónico por definir la noción de pecado oculto ;

- In cogitatione - in locutione -in opere: imprime un rumbo diferente a la exégesis. Desplaza la puesta en acto del pecado a la tercera instancia de la tríada. La novedad se centra particularmente en la segunda instancia. Fija un punto intermedio entre el pensamiento y la acción que viene dado por el lenguaje. De allí, la importancia que se otorga a la boca o la lengua y en varios casos se constata que la localización espacial del segundo muerto se desplaza de " extra portas » a « in porta », enfatizando así el carácter « liminar » del segundo elemento de la tríada ;

- Delectatio - consensus - actus : conecta a los tres muertos con el pecado de Adán y los hace conjugar con otra tríada, la conformada por Serpens-Eva-Adam. Este cuarto esquema se basa en la identificación directa entre la tríada de muertos y el process of sining sugestión-delectación-consenso. Asistimos aquí también al corrimiento del paso al acto a la tercera instancia de la tríada. Pero aquí se suma un nuevo desplazamiento en tanto se desdoblan delectación y consenso.

51 En Partidas, el tratamiento de esta alegoría presenta cierta dosis de originalidad y una considerable riqueza en vacilaciones y forzamientos de sentido. Todas sus versiones textuales - es decir, las sucesivas y variadas redacciones de la Primera Partida - piensan la imagen en términos generales a partir del tercer modelo relevado en las fuentes de origen eclesiástico : pensamiento, palabra y obra. Sin embargo, se registran diferencias textuales sustanciales que revelan un tipo de reflexión que se maneja mejor en el análisis de alegorías que en el despliegue proposicional.

Hallamos por un lado las versiones de López, Montalvo y Libro de las Leyes que se reducen a enunciar la identificación. El enxemplo de los resucitados transmite una clara idea secuencialidad que remite tanto al progresivo agravamiento de la falta como a su mismo proceso de constitución.

Un caso bien distinto presenta la versión de la Real Academia en P. I, 4, 62. Aquí se retoma la asimilación de la imagen de los tres muertos con la tripartición de pensamiento, palabra y obra. Sin embargo, se incluye un elemento nuevo que es la equiparación de los tres muertos con una tríada compuesta por las figuras del pecado venial, el criminal y el mortal. Este esquema se monta sobre la equiparación de tres tríadas : a) hija del sacerdote/ pecado por pensamiento/pecado venial; b) hijo de la viuda/pecado " por palabra » (o en preparativos)/pecado criminal ; c) Lázaro/pecado por obra/pecado mortal. Aquí también la secuencialidad es clara y responde asimismo a un criterio mixto de agravamiento, por un lado, y de orden psicogenético, por el otro. Dicho esto, queda claro que en este modelo el pecado criminal se halla en el centro de esta secuencia que plantea la existencia de tres tipos de pecado distintos y autónomos. Remarquemos: el pecado criminal es independiente del mortal o, en todo caso, constituye un estadio previo.

Por último, Setenario ofrece el tratamiento más ambiguo de la cuestión. El texto contempla también las tres tríadas pero en un esquema diferente al caso anterior. La principal divergencia pasa por la introducción en Setenario 98 de otro concepto de pecado criminal, cuya nota distintiva pasa por la existencia de penas ${ }^{35}$. La desvinculación con la idea de pecado "por palabra " se refuerza con el divorcio que se constata en Setenario entre la metáfora de los tres muertos y la tríada Venial-Criminal-Mortal. En efecto, el enxemplo de los resucitados se ubica en otra ley (Setenario 99) y las correspondencias son más vagas, 
incluso confusas. Este texto se encarga de mantener la primera y tercera correspondencias de tríadas que aparecían en la versión de la Academia. Pero respecto del hijo de la viuda, o sea, el pecado que sale del pensamiento, se abstiene de asimilarlo con el pecado criminal. La esencia del pecado criminal no parece jugarse en el proceso de constitución del pecado sino en su cruce con resultados en el orden de lo penal.

Pese a estas diferencias, el texto de Setenario repite la secuencialidad establecida en la articulación de las tres tríadas de la versión de la Academia y refuerza explícitamente la topología de centro y extremos de aquella versión, en unos términos que parecen expresar la idea de agravamiento ${ }^{36}$. En este sentido, el texto parece indicar una progresión

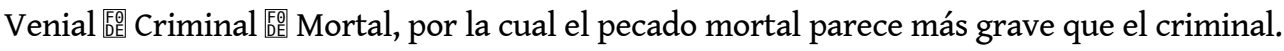
Pero el esquema no cierra y los ejemplos del texto cuestionan esta secuencialidad basada en la magnitud del pecado ${ }^{37}$. Pero, si la existencia de penas, y no la gravedad, es el criterio diferenciador, en el pecado criminal existiría un plus respecto del pecado mortal. De este modo, la secuencia vendría dada de la siguiente manera : Venial 熙 Mortal 豎 Criminal. La presencia de penas temporales como elemento diferenciador tampoco aporta suficiente claridad. Si el pecado criminal ha de entenderse como un pecado mortal que, además de la condena del alma, implica pena en el cuerpo, lo que lleva a confusión es tanto el hecho de presentar una tríada de pecados distintos y autónomos como la insistencia en ubicar al pecado criminal en el centro de esta topología secuencial.

En Partidas, entonces, el tratamiento de esta alegoría da pie a una reflexión teológicojurídica en torno de la noción de pecado criminal, que la diferencia de las exégesis tradicionales y también de las elaboraciones canónicas en torno de esta noción ${ }^{38}$. En efecto, el redactor de la Academia incluye referencias al pecado criminal aunque no parece adscribir a definición alguna de las ofrecidas en el derecho canónico. El redactor tal vez se vio tentado a jugar a las tríadas y por ello fuerza su inclusión en el esquema de los tres muertos. Sin embargo, el peculiar tratamiento que hace este texto puede en cierto sentido inscribirse en la búsqueda canónica. Quizá el redactor equipara pecado criminal con el hijo de la viuda porque entiende que para que un pecado sea crimen se necesita de la consumación en un hecho exterior y la metáfora del hijo de la viuda se define, precisamente, en el acto de exteriorización. Sólo cuando el cadáver ha cruzado las puertas de la ciudad, cuando se trasciende el fuero interno, es cuando el tribunal puede actuar y se está en presencia de un crimen. Desde este punto de vista, la asimilación con la categoría "céntrica " del hijo de la viuda no se entendería en términos de un agraviamiento del pecado en el process of sining sino a partir de lo que necesita el derecho como requisito para llamar crimen a un pecado.

Por su parte, el redactor del Setenario tanto incluye referencias al pecado criminal como remite a lo tratado en Graciano. Sin embargo, los dos forzamientos ya marcados - el pecado criminal como tercera categoría autónoma y como topos central de una secuencia de pecados - diferencian este tratamiento del que ofrece el texto canónico y generan incluso inconsistencias en el texto ${ }^{39}$. Podría pensarse que el redactor de Setenario experimenta al pecado criminal como algo que esencialmente se halla en el medio de dos polos - "éstos sson commo en medio ", dice el texto. Fuerza la centralidad y postula la «tercería » del pecado criminal por cuanto lo concibe como una entidad intermedia entre dos instancias - que nos vemos tentados a llamar religión y derecho. El carácter autónomo e intermedio le vendría de un cruce transversal a la secuencia Venial 熙 Mortal 熙 Criminal que el mismo texto se encarga de explicitar cuando analiza la derivación de pecado a pecado. La topología de medios y extremos no se definiría por 
la variable del monto de penas sino por la incorporación de una nueva dimensión, del cruce de otra variable que definiría dos espacios entre los cuales el pecado criminal funcionaría como pivote.

Pero así como la imagen de los tres muertos genera en Partidas esta reflexión teológicojurídica, también se puede suponer que da pie a una reflexión implícita de orden antropológico. De hecho, se trata de una metáfora habitualmente usada para graficar el desarrollo psicogenético del pecado. Si la imagen textual que producen estas vacilaciones es la de un pecado criminal definido como elemento flotante y pivote entre dos dimensiones, podría suponerse una imagen paralela respecto de la persona del pecador? Si fuera así, estos forzamientos de sentido en la lectura de la alegoría trasuntarían una concepción multidimensional de la persona, una "persona pivote " entre dos dimensiones graficadas en dos secuencias de distinta naturaleza : una que va desde el consenso interno hacia la perdición del alma - escala "religiosa» de agravamiento del pecado - y otra que va desde la exteriorización del yo interno - del cual el derecho parece no tener nada que decir - hacia la aplicación de penas en el cuerpo - reducido a lugar de ejecución de la pena. Se trata de imágenes difíciles de asir por cuanto lo que planteamos es una lectura sintomática que se construya a partir de las incoherencias y forzamientos de los textos. Donde hablamos de una reflexión teológico-jurídica y una antropológica, debemos suponer necesariamente un entrecomillado : más que una reflexión, nos hallamos ante tensiones que se operan en los textos y producen síntomas en las vacilaciones, las inconsistencias, etc.

En todo caso, lo que queremos sostener es que cualquier enunciado en torno del binomio pecado/delito y su relación con la persona resulta inescindible de su contexto de su enunciación. Es decir, toda aseveración general debería ir inextricablemente unida al despliegue del caso que enmarcó su construcción. De hecho, ni el ejemplo de los usos de la alegoría de los tres muertos ni el del adulterio desmienten específicamente la imagen general de cuasi indiferenciación pecado/delito - en un caso, por el carácter trunco que finalmente presenta el proceso de diferenciación ; en el otro porque, producida ésta en acto, es suturada a través del montaje de diversas operaciones discursivas. Pero es la perspectiva situacional centrada en figuras y mecanismos textuales específicos la que permite ver las operaciones puestas en juego (y sus límites) que dan como resultado tal imagen general.

Es en este sentido que planteamos el trabajo con síntesis textuales in actu entre los dispositivos teológico y jurídico de construcción de la persona. Nos interesa analizar si es posible - y cómo opera en la práctica - la combinación en un texto de una unidad abstracta que nace de la disociación de sujetos y cuerpos sin ligazón fuerte con un soporte individual (Thomas) con otra unidad también abstracta pero donde el cuerpo resulta imprescindible para su definición y donde la identidad individual es constitutiva (Boureau, Bynum, etc.).

61 Un escenario que trabajamos como caso de interacción entre los distintos dispositivos es el de la lógica que gobierna la instrumentación de castigos hereditarios en el derecho medieval, tal como expusimos en el encuentro de Auxerre. Nuestra investigación parte de la hipótesis de una posible articulación entre la práctica de los castigos hereditarios y la ficción de la identidad personal padres/hijos del derecho romano. Las tendencias del derecho medieval a traducir las ficciones personales clásicas de forma de no contradecir el principio de singularidad individual, por un lado, y a pensar los lazos de identidad personal en términos biológicos, por el otro, se presentan como un campo 
fértil para pensar la interacción de los dispositivos de construcción de la persona. Un ejemplo de esta articulación podría señalarse en la manera en que ha influido, respecto de la estipulación de penas por lesa majestad a hijos postea nati, la reflexión teológica en torno del criterio personaliter divisus para la transmisión del pecado original así como también los planteos anexos del traducianismo físico, descriptos por Philip Reynolds ${ }^{40}$.

Para finalizar, quisiéramos señalar que nuestro reclamo por una perspectiva situacional en el estudio de las relaciones pecado-delito-persona pretende adecuarse también a las formas medievales de pensar casuísticamente en derecho y teología. Por otra parte, pensar en situación se acuerda con la lógica de nuestro supuesto de una persona planteada como vector resultante de las distintas fuerzas que operan en su construcción. En este sentido, por último, esta problemática puede funcionar como una plataforma desde donde incursionar en las teorizaciones sobre las fuerzas, los dispositivos y las emergencias subjetivas en el discurso histórico.

\section{NOTAS}

1. Aaron Gurevich (Medieval popular culture. Problems of belief and perception, Cambridge, 1992), por ejemplo, resalta que el juicio que sufre cada hombre después de su muerte es pensado de forma individual y como en él se pesan las malas y las buenas acciones personales del difunto, se puede hablar de cierto individualismo. Sin embargo, el combate que se sucede en el momento del juicio entre sus pecados y sus virtudes, revela en realidad que las acciones, pensamientos y deseos del pecador operan en la exterioridad de su persona y en cierto sentido aparecen como independientes de su voluntad.

2. Desde el s. XI dos entidades se asocian indefectiblemente a cada cristiano, un ángel guardián y un diablo tentador, binomio cuyo rol en el proceso de individuación cristiana se ha de tener en cuenta. Cf. J. BASCHET, « Âme et corps dans l'Occident médiéval ", Archives de sciences sociales des religions, 112 (2000).

3. En efecto, la propia persona del pecador suele presentarse como una multiplicidad, alejada del carácter unitario que la subjetividad moderna asigna al individuo. Dado el caso, el yo del pecador puede ser objeto de un singular desdoblamiento como en el tratamiento teológico del suicidio en tanto pecado de desesperación, cuando se plantea el homicidio de sí mismo sobre la base de la fórmula « X asesinó a X ».

4. El propio cuerpo y/o sus órganos pueden aparecer imbuidos de categorías morales y concebidos como ejecutores responsables de los procederes humanos. Ello es evidente en el tratamiento que los teólogos hacen de los genitales como órganos independientes de la voluntad desde la Caída, con una relación íntima con el pecado, tanto por ser ocasión e instrumento, como porque su misma autonomía responde a una etiología pecaminosa. Pero atañe también a otras partes del cuerpo, como es el caso de la lengua estudiado por C. CASAGRANDE e S. Vecchio, Les péchés de la langue, París, 1991.

5. J-c. sснмітт, « La "découverte de l'individu" : une fiction historiographique? », in P. MENGAL Y F. PAROT, La fabrique, la figure et la feinte. Fictions et statut des fictions en psychologie, París, 1992. 
6. J.-C. SCHMITT, « La “découverte... », ibid.

7. C. MORRIS, The Discovery of the Individual (1050-1200), Toronto, $1995 \mathrm{e}$ « Individualism in twelfth-century religion. Some further reflections ", Journal of Ecclesiastical History, 31/2 (1980).

8. J. F. BENTON, « Consciousness of Self and Perceptions of Individuality », in R. BENSON e G. CONSTABLE, Renaissance and Renewal in the Twelfth Century, Toronto, 1999.

9. J. L. ROMERO, La revolución burguesa en el mundo feudal, México, 1989.

10. C. W. BYNUM, « Did the twelfth-century discover the individual ? ", Journal of Ecclesiastical History, 31/1 (1980), luego publicado en Jesus as Mother. Studies in the spirituality of the High Middle Ages (Berkeley, 1982).

11. J.-C. SCHMITT, « La "découverte... », op. cit.

12. A. GUREVICH, Los orígenes del individualismo europeo, Barcelona, 1997.

13. B. ClAVERo, Tantas Personas como Estados. Por una antropología política de la historia europea, Madrid, 1986, p. 78.

14. J. BASCHET, « Âme et corps... », op. cit.

15. No incluimos en este relevamiento el texto de O. LOTTIN, Psychologie et morale au XII et XIII siècles (Lovaina, 1942-1958). Texto absolutamente imprescindible y básico para casi todos los autores que tratan sobre el tema, conforma una gigantesca obra de consulta, imposible de reseñar en pocas palabras.

16. S. WENZEL, «The Seven Deadly Sins : Some Problems of Research », Speculum 43 (1968).

17. D. HOWARD, The Three Temptations : Medieval Man in Search of the World, Princeton, 1966.

18. D. ELLIOT, « Pollution, illusion and masculine disarray : nocturnal emissions and the sexuality of the clergy ", in K. LOCHRIE, P. MCCRACKEN y J. SCHULTZ, Constructing Medieval Sexuality, Minnesota, 1997.

19. A. BOUREAU, « La redécouverte de l'autonomie du corps : l'émergence du somnambule (XII ${ }^{\mathrm{e}}-\mathrm{XIV}^{\mathrm{e}}$ siècle) », Micrologus, I, 1993.

20. C. W. BYNUM, « Material continuity, personal survival and the resurrection of the body : a scholastic discussion in its medieval and modern contexts ", in Fragmentation and Redemption: Essays on Gender and the Human Body in Medieval Religion, New York, 1992. 21. T. GREGORY, « Per una fenomenologia del cadavere », Micrologus, 7 (1999).

22. M. VAN DER LUGT, « La personne manquée. Démons, cadavres et opera vitae du début du $\mathrm{XII}^{\mathrm{e}}$ siècle à saint Thomas ", Micrologus, 7 (1999).

23. Ү. тномAS, «El sujeto de derecho, la persona y la naturaleza. Sobre la crítica contemporánea del sujeto de derecho ", in Los artificios de las instituciones, Buenos Aires, 1999.

24. A. BOUREAU, « Droit et théologie au XIII ${ }^{\mathrm{e}}$ siècle », Annales ESC, 6 (1992).

25. B. ClAVERo, Tantas Personas como Estados. Por una antropología política de la historia europea, Madrid, 1986.

26. Cf. A. GUREVICH, Los orígenes..., op. cit., p. 205 sqq.

27. N. PARTNER, « No sex, no gender », Speculum, 68/2 (1993), p. 431.

28. A. BOUREAU, « Droit et théologie... », op. cit.

29. Un examen de este tipo de textos permite apreciar la necesidad de trabajos específicos que den cuerpo y sustancia a unas tendencias históricas de largo plazo dibujadas con trazos demasiado amplios. Tres posiciones - no totalmente comparables en virtud del lugar que ocupa cada una en el marco de sus respectivas armazones podrían ser señaladas a fin de graficar a partir de las disparidades que presentan el vacío sobre el que se opera. A partir del trabajo de R. Bartlett sobre las ordalías por 
fuego y agua, se puede pensar el final del siglo XII y principios del XIII como el momento de un proceso « whereby an increasingly sharp distinction was drawn between sin and crime » (R. BARTLETT, Trial by fire and water, Oxford, 1986, p. 81). En cambio, según el estudio de M. Foucault acerca de las relaciones entre las formas de la verdad y las prácticas jurídicas, es precisamente a finales del XII con el inicio de la indagación judicial cuando se comenzaron a conjugar las nociones de infracción a la ley y de falta religiosa (M. FOUCAULT, La verdad y las formas jurídicas, Barcelona, 1980, p. 83-84). Por último, tenemos el trabajo de Clavero (B. CLAVERo, « Delito y Pecado. Noción y escala de transgresiones ", in F. TOMÁs Y VALIENTE, dir., Sexo Barroco y otras transgresiones premodernas, Madrid, 1990, p. 57-89) donde afirma que en los siglos XII y XIII « diferencia sustancial entre delito y pecado no se aprecia » como tampoco la habrá en los siglos XVI y XVII que trabaja en su texto (B. CLAVERo, « Delito... », ibid., p. 60 sqq.). De este modo, apreciamos una postura que percibe un proceso de diferenciación entre pecado y delito en el XIII, otra en las antípodas que afirma una conjunción para el mismo período y una tercera que, ignorando los procesos de transformación que señalan las dos previas, desplaza el momento de cambio para varios siglos después (tesis que sostiene también P. Prodi (Una storia della giustizia. Dal pluralismo dei fori al moderno dualismo tra coscienza e diritto, Bolonia, 2000). Desde este paisaje es que pretendemos abordar un estudio del tema centrado en el siglo XIII pues a nuestro entender es claro que, por lo menos, no resulta un momento indiferente para la cuestión tratada.

30. B. CLAVERO, « Delito... », ibid.

31. L. DUMONT, Essays on Individualism. Modern Ideology in Anthropological Perspective, Chicago, 1986.

32. Respecto del judaísmo antiguo y su rol en la historia del individuo occidental, $c f$. op. cit., p. 25. Para el s. XII, cf. p. 53. El s. XV parece figurar como la fecha de nacimiento efectivo, cf. p. 157 (con referencias a L. Dumont). Cf. también p. 163 y 169.

33. B. CLAVERO, « Delito... », op. cit.

34. TOMÁS SÁNCHEZ, De sancto matrimonii sacramento disputationum, Viterbo, 1754, lib. 10, disp. 8, num. 37.

35. El pecado criminal ya no aparece aquí ligado a la definición del pecado « por palabra ». No son los actos preparatorios del pecado ni el momento en que se exteriorizan los malos pensamientos los que definen la instancia del pecado criminal sino la aparición de una infamia que afecta al pecador " en ssu onrra e en ssu ffama ", un tipo de pecado que es también crimen y por ello implica « pena tan bien en el cuerpo commo en el alma »: « Peccados ffazen los omnes de muchas naturas, segunt la uoluntad les da e los ffechos sse los guisan, pero todos tornan en tres maneras : la vna, venial ; la otra, criminal ; la otra, mortal [...] La ssegunda es de los criminales, et éstos sson commo en medio. Et sson peccados muy ssin guisa, por que aquellos que los ffazen mereçen auer pena tan bien en el cuerpo commo en el alma [...] conuyene que se diga de los criminales, que sson muy ffuertes e sse ffazen mucho atreuidamiente e con grant osadía; ca tanto quier dezir crimen commo peccado mucho atreuido, por que el que lo ffaze vale mucho menos que ante que lo ouyese ffecho en ssu onrra e en ssu ffama. Et esto sse departe en [dos] maneras: la vna que tanne en los ffechos spirituales que pertenesçen a Santa Eglesia ; la otra, en los sseglares que pertenesçen al mundo. » Setenario, ed. K. VANDERFORD, Buenos Aires, 1945.

36. «Et quáles sson peccados criminales e por qué los llaman assí. Comienço e medio e acabamiento an todas las cosas naturalmiente. Et los dos cabos, el primero e el postremero, sson los más fflacos que el de medio, porque el que comiença ua ssubiendo, e el que acaba es ya en la ffin et 
non puede yr más adelante. Mas el que es en medio ya a ssobido quanto pudo ssobir, et está la ssu ffortaleza atreuyéndosse commo [començó] osadamiente e leuó ssu ffecho más adelante que pudo. Et por ende a ssemeiante desto sson las tres maneras de peccados. La primera es de los veniales, que dixiemos que sson comienço para poder ssobir a los otros. La ssegunda es de los criminales, et éstos sson commo en medio. Et sson peccados muy ssin guisa, por que aquellos que los ffazen mereçen auer pena tan bien en el cuerpo commo en el alma. La terçera es de los mortales, e esto es ya ffin de todo el mal porque el alma ha mortal pena, commo quier que ella en ssí non puede morir. "

37. Cf. J. CRADDOCK, « Los pecados veniales en las Partidas y en el Setenario : Dos versiones de Graciano, Decretum D. 25 c. 3 », Glossae, 3 (1991).

38. Cf. S. KUTTNER, Kanonistische Schuldlehre von Gratian bis auf die Dekretalen Gregors IX, Ciudad Vaticano, 1935 y H. BERMAN, La formación de la tradición jurídica de Occidente, México, 1996.

39. En Setenario, por ejemplo, se expresa claramente que el centro de la secuencia es mayor que sus extremos ( Comienço e medio e acabamiento an todas las cosas naturalmiente. Et los dos cabos, el primero e el postremero, sson los más fflacos que el de medio »). Pero si el pecado mortal incluyese al criminal -tal como postularía Abelardo y tal como lo indica la secuencia Mortal 醩 Criminal explicitada en la misma Setenario 98-, el pecado mortal debería ser numéricamente mayor.

40. Cf. P. REYNOLDS, Food and body. Some peculiar questions in high medieval theology, Leiden/ Boston/Colonia, 1999.

\section{ÍNDICE}

Mots-clés: péché, individu, anthropologie chrétienne

\section{AUTOR}

\section{ALEJANDRO MORIN}

Universidad de Buenos Aires 